\title{
Regulation of Human Bone Marrow-derived Osteoprogenitor Cells by Osteogenic Growth Factors
}

\author{
Michael W. Long, * J. A. Robinson, ${ }^{\star}$ E. A. Ashcraft, ${ }^{*}$ and Kenneth G. Mann \\ *Department of Pediatrics, University of Michigan, Ann Arbor, Michigan 48109; and ${ }^{\ddagger}$ Department of Biochemistry, \\ University of Vermont, Burlington, Vermont 05405
}

\begin{abstract}
Human bone marrow contains a distinct cell population that expresses bone proteins and responds to transforming growth factor $\beta 1$ (TGF- $\beta$ ), but not to hematopoietic growth factors (Long, M. W., J. L. Williams, and K. G. Mann. 1990. $J$. Clin. Invest. 86:1387-1395). We now report the isolation, characterization, and growth factor responsiveness of these precursors to human osteoblasts and the identification of a human osteoprogenitor cell. Immunological separation of human bone marrow nonadherent low-density (NALD) cells results in a marked enrichment of cells that express osteocalcin, osteonectin, and bone alkaline phosphatase. Flow cytometric analyses show that distinct cell subpopulations exist among these isolated cells. The majority of the bone antigen-positive cells are approximately the size of a lymphocyte, whereas other, less frequent antibody-separated subpopulations consist of osteoblast-like cells and osteoprogenitor cells. In serum-free cultures, TGF- $\beta$ stimulates the small, antigen-positive cells to become osteoblastlike, as these cells both increase in size, and express increased levels of osteocalcin and alkaline phosphatase. Antibody-separated cells also contain a separate population of clonal progenitor cells that form colonies of osteoblast-like cells when cultured in serum-free, semi-solid media. Two types of human osteoprogenitor cells are observed: a colonyforming cell (CFC) that generates several hundred bone antigen-positive cells, and a more mature cluster-forming cell that has a lesser proliferative potential and thus generates clusters of 20-50 antigen-positive cells. Osteopoietic colony-forming cells and cluster-forming cells have an obligate but differential requirement for osteogenic growth factors. The CFCs respond to TGF- $\beta$, basic fibroblast growth factor (bFGF), bone morphogenic protein-2 (BMP-2), and 1, 25-dihydroxy vitamin $D_{3}\left(1,25-O H D_{3}\right)$. In contrast to the colony-forming cells, cluster-forming cells are regulated predominately by $1,25-\mathrm{OH} \mathrm{D}_{3}$ and TGF- $\beta$, but fail to respond to bFGF. We conclude that human bone marrow
\end{abstract}

Address correspondence to Michael W. Long, University of Michigan, 1500 East Medical Center Drive, Room 3570B, MSRB-II, Box 0688, Ann Arbor, MI 48109-0688. Phone: 313-747-2893; FAX: 313-7639512.

Received for publication 11 March 1994 and in revised form 23 September 1994.

J. Clin. Invest.

(C) The American Society for Clinical Investigation, Inc. 0021-9738/95/02/0881/07 \$2.00

Volume 95, February 1995, 881-887 contains a nonhematogenous, heterogeneous population of bone precursor cells among which exists a population of proliferating osteoprogenitor cells. Further characterization of these bone precursor cell populations should yield important information on their role in osteogenesis in both health and disease. (J. Clin. Invest. 1995. 95:881-887.) Key words: osteoprogenitor cells - growth factors - preosteoblasts $\cdot$ osteoblasts

\section{Introduction}

Bone development results from the proliferation of mesenchymal cells, their differentiation into osteogenic progenitor cells, and the eventual calcification of cartilage and bone extracellular matrix (1). During this developmental process, bone also forms a central marrow in which hematopoietic cell differentiation occurs. One of the unresolved areas concerning bone formation is the nature of the developmental lineage ( $\mathrm{s}$ ) leading to the formation of each bone cell type: the osteoblast and osteoclast. Previous studies suggest that osteoblasts arise in some unknown manner from local mesenchymal cells $(2,3)$, whereas osteoclasts may be the progeny of macrophages/monocytes $(2,4-$ $6)$. However, exact information concerning the nature of the stem cell population ( $s$ ) capable of both proliferating and differentiating into bone-forming osteoblasts is limited. We report the isolation and characterization of human bone precursor cells from nonadherent low-density (NALD) ${ }^{1}$ bone marrow cell populations. Isolated bone precursor cells are of three types: osteoprogenitor cells, preosteoblast, and osteoblast-like cells. Each of these subpopulations shows a differential responsiveness to osteogenic stimuli.

\section{Methods}

Bone marrow cell preparation and cell culture. Human bone marrow aspirates were obtained from normal volunteers after informed consent. Bone marrow cells were subjected to adherent cell depletion and density separation techniques as described previously (7). Briefly, NALD cells were prepared by first subjecting the cells to equilibrium-density centrifugation (Ficoll; Sigma Chemical Co., St. Louis, MO). The resultant mononuclear, low-density cells (i. e., those cells at the Ficoll interface of $\sim 1.077 \mathrm{~g} / \mathrm{cm}^{3}$ ) next were subjected to two rounds of plastic adherence (to remove marrow stromal cells) (8) and these NALD cells were then subjected to immune-adherence isolation (see below). Bone cells

1. Abbreviations used in this paper: bFGF, human recombinant basic fibroblast growth factor; BGP, bone gla-protein; BMP-2, bone morphogenic protein-2; CFC, colony-forming cell; CFU-f, colony-forming unit fibroblast; NALD, nonadherent low-density; $1,25-\mathrm{OH} \mathrm{D}_{3}, 1,25$-dihydroxy vitamin $D_{3}$. 


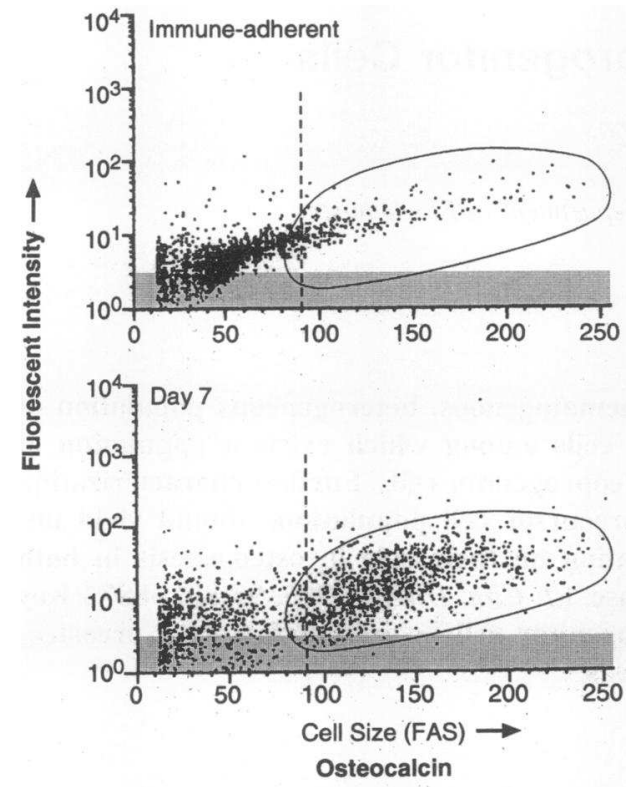

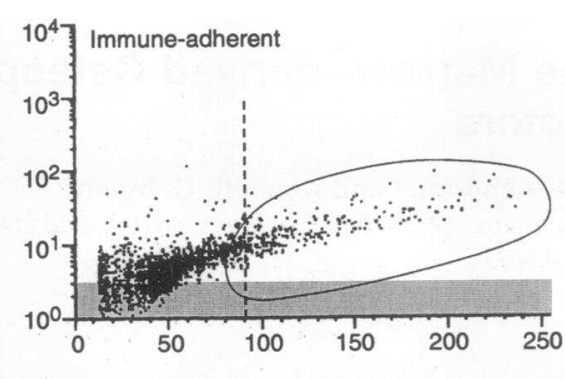

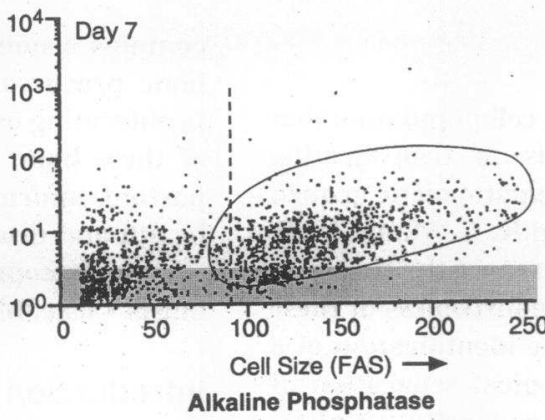

Figure 1. Flow cytometric analysis of immune-adherent bone marrow-derived bone precursor cells. Human NALD bone marrow cells were incubated on antibody-coated tissue culture dishes (see Methods) and the adherent cells were analyzed by flow cytometry. (Top) Immune-adherent bone cell populations were analyzed for expression of bone proteins (osteocalcin, left; bone alkaline phosphatase, right) as well as cell size (forward-angle light scatter, FAS). Antigen-positive cells are identified as those cells with more fluorescence than the upper limit of nonspecific fluorescence seen in antibody controls (shaded areas). Osteoblast-like cells (circled) were identified as those bone protein antigen-positive cells significantly larger than the upper $95 \%$ cell size limit for input NALD cells (dashed line) as well as parallel analyses of human osteoblasts (see Methods). (Bottom) Flow cytometric analysis of immune-adherent cells cultured for 7 $\mathrm{d}$ in the presence of $25 \mathrm{pM}$ TGF- $\beta$. This is a single representative figure of multiple flow cytometric analyses from four separate bone marrow donors. were cultured in supplemented McCoy's 5A medium (Gibco, Grand Island, NY) (7) containing 1\% ITS + (Collaborative Research Inc., Bedford, MA) as described previously (9).

Antibodies, immune adherence, and immunochemistry. The expression of bone protein antigens was determined by fluorescence activated flow cytometry (below) or by immunocytochemistry using an avidinbiotin system as previously described from this laboratory $(8,9)$. These antibodies are specific for their respective antigens and do not crossreact with other matrix proteins $(10,11)$. The monoclonal antibody to alkaline phosphatase (SAOS2-P80) was raised to osteosarcoma cells as described elsewhere (11). This antibody was proven to detect alkaline phosphatase activity by immunoprecipitation, and by direct protein sequence analysis of the precipitated antigen (data not shown). For immune adherence, monoclonal antibodies to osteocalcin and osteonectin were immobilized onto tissue culture plastic using a procedure described previously (12). Briefly, antibody solutions $(10 \mu \mathrm{g} / \mathrm{ml})$ in PBS (pH 7.4) are immobilized by adsorption onto tissue culture plastic for 12 $18 \mathrm{~h}$ at $37^{\circ} \mathrm{C}$. Antibodies are removed and the plates were washed three times with PBS. Next, nonspecific binding sites are blocked by incubating the plates for $1 \mathrm{~h}$ at $37^{\circ} \mathrm{C}$ with $1 \%$ BSA. For cell adhesion, 2.5-6.5 $\times 10^{5}$ NALD cells per $\mathrm{cm}^{2}$ (suspended in serum-free McCoy's medium containing $1 \% \mathrm{BSA}$ ) were incubated on antibody-coated dishes for $1 \mathrm{~h}$ at $37^{\circ} \mathrm{C}$. A uniform distribution of cells is ensured by gentle rotation of the dish every $15 \mathrm{~min}$. Subsequently, nonadherent cells were removed with three rounds of gentle washing using serum-free McCoy's medium containing $1 \%$ BSA. The immune-adherent cells were removed with the aid of a rubber policeman and analyzed for flow cytometry (as input cells) or cultured for $7 \mathrm{~d}$ in situ in the presence or absence (media controls) of osteogenic growth factors.

Flow cytometric analysis. Flow cytometric analysis was performed using a FACSCAN ${ }^{\circledR}$ system and data analyzed with the Lysis software program (both from Becton Dickinson, Mountain View, CA). Controls consisted of autofluorescence as well as nonspecific fluorescence detected with isotype-specific murine monoclonal antibody to keyhole lymphet hemocyanin obtained from Becton Dickinson. Human osteoblast cell lines (MG63, SAOS2) were stained with monoclonal antibodies to osteocalcin and alkaline phosphatase (above), respectively, and analyzed for fluorescence intensity versus size (forward angle scatter) versus cellular complexity ( side scatter) to independently map the position of osteoblast-like cells in immune isolated bone marrow cell populations. The frequency of osteoblast-like cells was defined as the number of cells occurring in the osteoblast cell region (as defined above; Fig 1 , circled) expressed as a percentage of total bone antigen-positive cells.

Preosteoblast and osteogenic colony-forming cell cultures. In preosteoblast differentiation studies, immune-adherent cells (see Results and Discussion ) are cultivated under serum-free conditions in ITS/McCoy's (as above), containing 25 pM TGF- $\beta$ (Collaborative Research Inc.) For flow cytometric analysis, cells were harvested immediately after immune adherence (as day 0 or input) and on day 7 , either with a rubber policeman or by trypsinization using trypsin/EDTA (Gibco). The antigenic profiles of bone proteins are equivalent with either procedure (not shown), but scraping tends to reduce the total cell recovery. To quantify osteoprogenitor cells in immune-adherent cultures, adherent cells were cultured in situ in a fibrin-clot system. In these assays, immune-adherent cells (as above) are first checked microscopically to insure that no cell aggregates are present and then over-layered with fibrinogen-containing media which also contained the given amounts of the indicated osteogenic growth factors. A given growth factor was present for all $7 \mathrm{~d}$ of the culture period. Adherent cells are overlayered with McCoy's/ITS + media containing plasminogen-free fibrinogen (2 $\mathrm{mg} / \mathrm{ml}$ ) (Hematologic Technologies, Burlington, VT). The fibrinogen is then treated with human thrombin $(1 \mathrm{U} / \mathrm{ml})$ to form a fibrin clot. The known capacity of osteoblasts to produce proteolytic enzymes and thus lyse the clot was overcome by using epsilon-amino caproic acid at a concentration of $5 \mathrm{mM}$ and repletion with more fibrinogen, as needed. Additional fibrinogen is usually required on days 3 and 5 . Immunocytochemistry for osteocalcin expression in osteoprogenitor cell colonies was performed as previously reported (9), except that diaminobezadine concentration was $3 \mathrm{mg} / \mathrm{ml}$ and the substrate incubation period was increased to $2 \mathrm{~h}$. Immunocytochemistry controls consisted of an inappropriate antibody, secondary antibody only, and diaminobezadine only (to assess endogenous peroxidase activity). These controls were uniformly negative (data not shown).

\section{Results and Discussion}

Isolation and enrichment of bone protein-expressing cells. A number of noncollagenous proteins play a role in bone formation. We used monoclonal antibodies to two of these bone proteins, osteocalcin and osteonectin, both as phenotypic markers of bone cell development and as a mechanism of isolating bone 
protein-expressing cells in vitro. Osteonectin (also known as SPARC) is present in high concentration in bone of the axial skeleton and skull $(13,14)$. Osteonectin binds to calcium, hydroxyapatite, and collagen and, thus, may regulate mineral deposition in bone matrix (15). Another bone protein, osteocalcin (also known as bone gla-protein or BGP), is a vitamin Kdependent protein that is specific for bone and also binds calcium (15-18). We also used a monoclonal antibody to bone alkaline phosphatase (see Methods) as a phenotypic marker for bone cells. Our previous data demonstrated that marrow-derived osteoblast-like cells modify extracellular matrix in an osteogenic fashion (9). Coupled with the present data on antigenic phenotyping and in vitro expansion (see below), we herein define marrow-derived preosteoblasts as small, proliferating cells (lymphocyte-sized) that express low amounts of bone protein antigens, whereas marrow-derived osteoblast-like cells are the larger, differentiated progeny of these cells which express high amounts of antigen and, with longer culture (see reference 9), generate osteoid-like matrix.

Monoclonal antibodies to osteocalcin and osteonectin (10, 11) were used to capture ("pan") bone protein-expressing NALD cells using conventional immune-adherence technology $(19,20)$. Immune-adherence isolation produces a markedly enriched population of cells that are $40-60 \%$ bone protein antigen-positive. Subpopulations of these cells are further resolved using multiparameter fluorescence-activated flow cytometry (Fig. 1). The first subpopulation comprises the majority of the cells and is distinguished as a group of bone antigen-positive preosteoblasts approximately the size of a lymphocyte. A second population of antigen-positive osteoblast-like cells is larger than the upper $95 \%$ limit of unfractionated NALD cell populations and comprises $\sim 2-4 \%$ of the immune-adherent cell population (Fig. 1, top). Both antigen-positive small and large cells express osteocalcin, bone alkaline phosphatase (Fig. 1, top), and osteonectin (not shown). The exact developmental level at which bone precursor cells express these antigens is unknown. However, preliminary two-color fluorescence cytometry studies indicate that the majority ( $\geq 70 \%$ ) of the immune-isolated cells coexpress both osteonectin and BGP, whereas the remainder express either osteocalcin or osteonectin.

In vitro expansion and differentiation of bone marrowderived bone cells. Immune-isolated cells were cultivated under serum-free conditions in the presence of TGF- $\beta 1$. Multi-parameter flow cytometry indicates that TGF- $\beta$ treatment causes the small cells to differentiate into large, bone protein antigen-positive cells (Fig. 1, bottom). After $7 \mathrm{~d}$ of serum-free culture, the majority of immune-isolated cells show an approximate threefold increase in cell size (as defined by forward-angle light scatter) and a coordinate increase in their antigenic content, as demonstrated by a $0.5-1.0-\log$ increase in relative fluorescence. This observation confirms and extends our previous report showing that unfractionated marrow NALD cells contain bone precursor cells which, in long-term, serum-replete cultures, acquired the morphological and functional characteristics of osteoblasts (9). Thus, these osteoblast-like cells produced bone proteins and deposited these proteins into the extracellular matrix that, subsequently, begins mineralization (as indicated by cellular deposition of calcium into the matrix and positive von Kossa staining) (9). Examination of such osteoblast-like cells in the present report demonstrates that their frequency increases approximately four- to fivefold in the presence of TGF- $\beta$ (Fig. 2 $A)$. This increased cell frequency is due to either increased proliferation or the maintenance of bone protein antigen-posi-

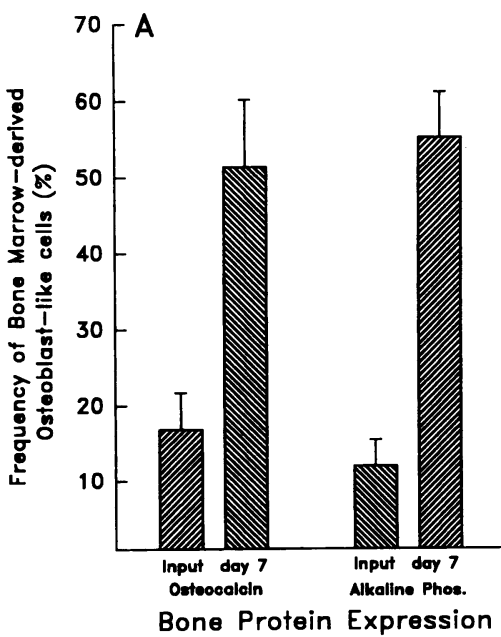

Figure 2. In vitro expansion of TGF- $\beta-$ stimulated bone marrow-derived osteoblasts. $(A)$ Increases in osteoblast-like cell frequency. After $7 \mathrm{~d}$ of culture in the presence of 25 pM TGF$\beta$, the frequency of osteoblast derived from small, bone protein antigen-positive cells was determined by flow cytometric analysis as described in Fig. 1. These data show a four- to fivefold increase in the frequency of osteoblastlike cells expressing osteocalcin (BGP) or alkaline phosphatase. Values are mean \pm SEM from four separate bone marrow donors. Day 7 values are significantly different ( $P \leq 0.05$, Student's $t$ test) from input immuneadherent (i. e., day $0, I n$ put) values. (B) Total osteoblast-like cells per culture. To determine that in vitro bone cell expansion occurred, the total osteoblast cell content of the culture was calculated based on the antigen-positive osteoblast frequency and total cellularity of these cul-

tures. These studies indicate an approximate three- to fourfold increase in osteoblast-like cells expressing osteocalcin or alkaline phosphatase. Day 7 values are significantly different $(P \leq 0.05$, Student's $t$ test) from immune-adherent day 0 (Input) values.

tive cell numbers during the loss of nonspecific (i. e., antigennegative) cell populations. Confirming the former, examination of the total cellularity per culture shows an approximate threeto fourfold in vitro expansion in the total number of osteoblastlike cells over a 7-d period (Fig. $2 B$ ), while the antigennegative cell number remains unchanged or diminished (not shown). This is true for both BGP-expressing cells as well as alkaline phosphatase-positive cells. These data do not, however, exclude the formal possibility that the small preosteoblastlike cells die off in culture while the larger osteoblast-like cells proliferate to become the predominant cell population. However, we consider this possibility unlikely as osteoblasts have low, if any, proliferative capacity. We conclude that it is more likely that immune selection of bone protein antigen-positive cells yields a TGF- $\beta$-responsive population of small preosteoblasts that is capable of differentiating into osteoblast-like cells. In either case, the result is an in vitro expansion of osteoblastlike cells.

In vitro development of human osteoprogenitor cells. We hypothesized that among the immune-isolated bone precursor cells there might exist a true bone progenitor cell, i. e., precursor cells capable of undergoing clonal expansion into differentiated 
progeny. The clonal nature and in vitro characteristics of progenitor cells in other systems are well described: progenitor cell growth and development requires the presence of at least one mitogenic growth factor, and cell growth in an inert, semi-solid 3-dimensional matrix which results in the clonal formation of cell colonies by restricting the outgrowth of differentiated progeny (reference 21 and references therein). To detect osteoprogenitor cells, immune-isolated NALD cells were over-layered with chemically defined, serum-free media containing fibrinogen, which is subsequently treated with thrombin to form a fibrin clot. Cells were cultured for $7 \mathrm{~d}$ under serum-free conditions in the presence of TGF- $\beta$ (or other growth factors, see below). Subsequently, the fibrin clot was dried to a film, and the cultures were subjected to immunocytochemical analysis.

Two types of progenitor cell-derived colonies are observed after $7 \mathrm{~d}$. One colony phenotype consists of small clusters of cells containing 20-50 osteocalcin-positive cells (Fig. $3 \mathrm{~A}$ ). By convention, this type of progenitor cell is referred to as a cluster-forming cell $(21,22)$ and represents a progenitor cell with limited proliferative potential. The second type of osteogenic cell growth consists of colonies containing several hundred intensely osteocalcin-positive cells (Fig. $3 \mathrm{~B}$ ). This latter type of colony-forming cell (CFC) thus represents an osteoprogenitor cell with an increased proliferative potential. Under appropriate growth factor conditions ( see below), this type of progenitor cell is present at 20-50 CFC per $10^{5}$ total immune-adherent cells. Both colony types are observed in the same cultures. The relationship between the number of adherent cells cultured and number of colonies observed is linear, thus demonstrating that colony formation is clonal (i. e., one progenitor cell gives rise to one colony) (Fig. 4). These two types of progenitor cell growth are consistent with previous observations in other systems in which CFC are felt to be more primitive than clusterforming cells $(21,22)$. Therefore, the cluster-forming cell represents a later (more mature) stage of bone cell development than the CFC (i. e., the CFC colony is developmentally antecedent to the CFC cluster).

Both cluster-forming and colony-forming osteoprogenitor cells show an obligate requirement for growth factors and a differential responsiveness to bone-regulatory cytokines (Fig. 5 ). Both progenitor cell types fail to develop in the absence of osteogenic growth factors (media controls, Fig. 5), whereas the addition of recombinant human growth factors known to regulate osteoblasts $(23-27)$ stimulates both cluster and colony formation. The colony-forming progenitor cells respond equally well to TGF- $\beta$ and human recombinant basic fibroblast growth factor (bFGF), generating $\sim 40-60$ colonies per $10^{5}$ cells (Fig. $5 \mathrm{~A})$. Likewise, 1,25 -dihydroxy vitamin $\mathrm{D}_{3}\left(1,25-\mathrm{OH} \mathrm{D}_{3}\right)$ and bone morphogenic protein-2 (BMP-2) both stimulate CFC but to a lesser degree than that seen with TGF- $\beta$ or bFGF. In contrast to the CFC, progenitor cells which form clusters respond well to $1,25-\mathrm{OH} \mathrm{D}_{3}$, whereas they respond less well to BMP-2 and TGF- $\beta$ (Fig. $5 B$ ). Of interest, bFGF fails to drive the formation of osteogenic clusters, suggesting a role for this growth factor only in the early phases in bone progenitor cell development.

One of the difficulties in dissecting cell lineages is the need to precisely define developmental stages. We combined immune-isolation, flow cytometric multiparameter analysis, and functional assays (colony formation and growth factor responsiveness) to characterize human marrow-derived bone precursor cells. Thus, the proliferative component of this lineage consists of two types of osteoprogenitor cells (the colony- and clusterforming cells) as well as the preosteoblasts, each distinguished by their cell size, growth factor responsiveness, and proliferative potential. The remaining isolated bone cells are the osteoblastlike cells that express increased amounts of bone proteins in response to TGF- $\beta 1$, have a low proliferative potential (if any ), and elaborate and mineralize a collagen and noncollagenous bone protein-containing extracellular matrix (reference 9 and data therein). As a matter of definition, a progenitor cell is a proliferating precursor cell that is restricted to a given lineage (in this case, osteoblastic) and is capable of generating clonal, differentiated progeny. During its development, this cell progressively looses its proliferative capacity, differentiating into an end-stage cell (e. g., an osteoblast). The in vitro correlate of this process is the formation of a colony, or cluster, respective to the progenitor cell's proliferative potential. As stated, we observe one colony phenotype which consists of small clusters of cells containing 20-50 osteocalcin-positive cells, and a second colony type of several hundred intensely osteocalcin-positive cells. This latter type of CFC thus represents an osteoprogenitor cell with an increased proliferative potential. Therefore the cluster-forming cell represents a later (more mature) stage of bone cell development than the CFC (i. e., the CFC colony is developmentally antecedent to the CFC cluster). The literature on the growth characteristics of these two progenitor types extends over $30 \mathrm{yr}$ and is too large to review here (for review see reference 28 and references therein). However, it is a logical and reasonable interpretation of the composite data that clusterforming cells are the progeny of CFC and that these exist as distinct cell subpopulations. While the literature predominately concerns hematopoietic cells, we have shown equivalent growth characteristics for osteoprogenitor cells. Moreover, we also have show each to have a differential responsiveness to stimuli, which is a defining characteristic of differing cell subpopulations. Finally, this nomenclature serves to define the morphological phenotype of osteoprogenitor cell growth observed in vitro. Thus, we have kept the distinction of colony- and cluster-forming progenitor cells for human osteoprogenitor cells. We therefore propose that osteoprogenitor cells are antecedent to boneforming cells in the following differentiation cascade: colonyforming cell $\rightarrow$ cluster-forming cell $\rightarrow$ preosteoblast $\rightarrow$ osteoblast.

Bone precursor cells coexist among a population of hematopoietic progenitor cells which can be separated from their differentiated progeny by physical methods (i. e., equilibrium density separation, plastic adherence). We demonstrated previously that

Figure 3. Human bone marrow-derived osteoprogenitor cell colonies. Immune-adherent bone antigen-positive cells were cultured in serum-free tissue culture medium (9) containing plasminogen-free fibrinogen, which was treated with thrombin (35) to form a fibrin clot. After $7 \mathrm{~d}$ of culture, the fibrin clots were dried to a film and subjected to immunocytochemical analysis using monoclonal antibodies to human BGP (osteocalcin) as described elsewhere (10). (A) Progeny of osteoprogenitor cluster-forming cells. Progenitor cells having a limited proliferative potential form small clusters (arbitrarily defined as $<50$ cells per cluster) of osteocalcin-positive cells. $(B)$ Clonal progeny of osteoprogenitor CFC ( $>50$ cells) are observed in a greater frequency than clusters and usually contain up to several hundred osteocalcin-positive cells. 

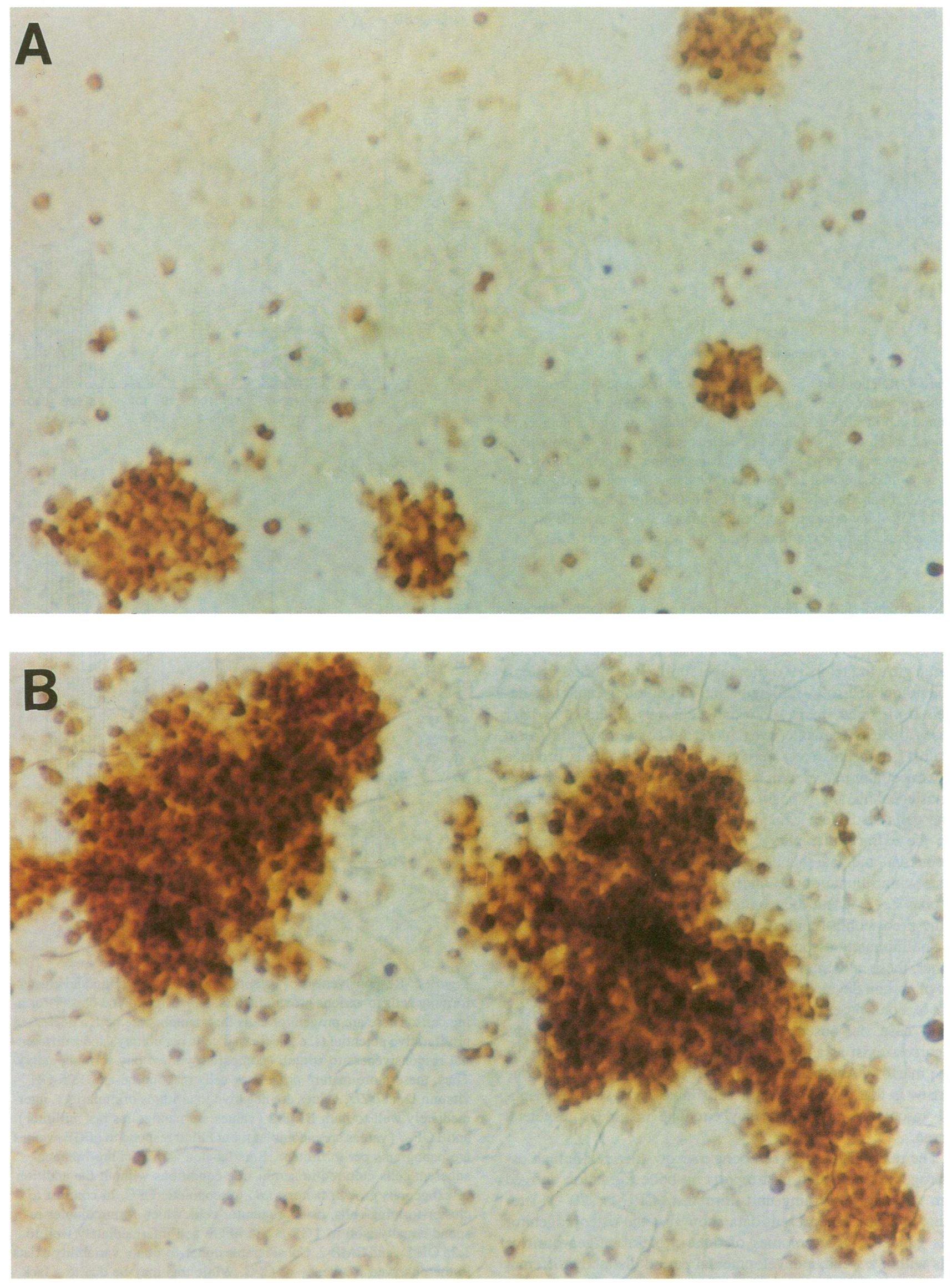


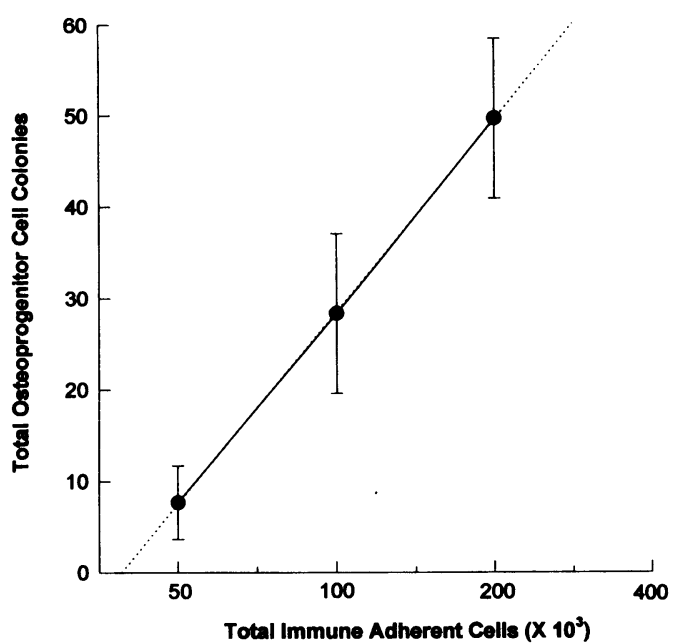

Figure 4. Relationship of osteoprogenitor cell frequency to the number of bone precursor cells cultured. Human osteoprogenitor cells were cultured and identified as described in Methods, varying the number of immune-adherent cells cultured at each point. The solid symbols/line represents the mean $\pm S D$ of three replicate cultures per point. The dotted line is the mathamatical regression of the data. The regression is linear $(P \leq 0.001)$ and the $Y$ intercept is not significantly different from zero (i. e., one colony arises from one progenitor cell). The results are a single representative experiment from four separate donors.

bone marrow-derived bone precursor cells were not hematogenous in origin, as these cells did not express the pan-hematopoietic cell surface antigen CD34 and failed to respond to hematopoietic growth factors (9). Moreover, unlike the murine system, human bone marrow-initiated bone cell cultures cannot be derived from bone marrow stromal cells (9). Finally, in later phases of development (i. e., in serum-containing, long-term cultures), bone marrow-derived osteoblast-like cells produce an extracellular matrix which contains type I collagen, osteonectin, osteocalcin, and is positive in the von Kossa reaction; these bone cells also were capable of depositing calcium $\left({ }^{45} \mathrm{Ca}^{2+}\right)$ into the extracellular matrix (9). These observations and the present data indicate that a separate lineage of osteopoietic cells exists within human bone marrow. The data also suggest that, at some stage during their ontogeny, bone precursor cells such as the preosteoblast and, in particular, the osteoprogenitor cell are not intimately associated with the endosteal surface of bone. Rather, these cells may migrate to the endosteum upon acquisition of certain developmental characteristics, such as the expression of bone protein (or other extracellular matrix) receptors. In any case, our observations strongly suggest that osteogenic precursors exist as a reservoir of bone-forming cells within the bone marrow. Another correlate of this localization to the bone marrow is that osteoprogenitor cells have access to the peripheral vasculature and, thus, may circulate in times of skeletal trauma.

The relationship between bone marrow-derived human osteoprogenitor cells and past reports on bone formation derived from the colony-forming unit fibroblast (CFU-f) (29-31) remains unclear. The present data show that the osteoprogenitor cells generate large colonies of bone protein antigen-positive cells within a week, a developmental period distinctly different from that of CFU-f-derived bone formation (32). Examination of the human osteoprogenitor cells during development indicates that these precursor cells do not generate progeny with a
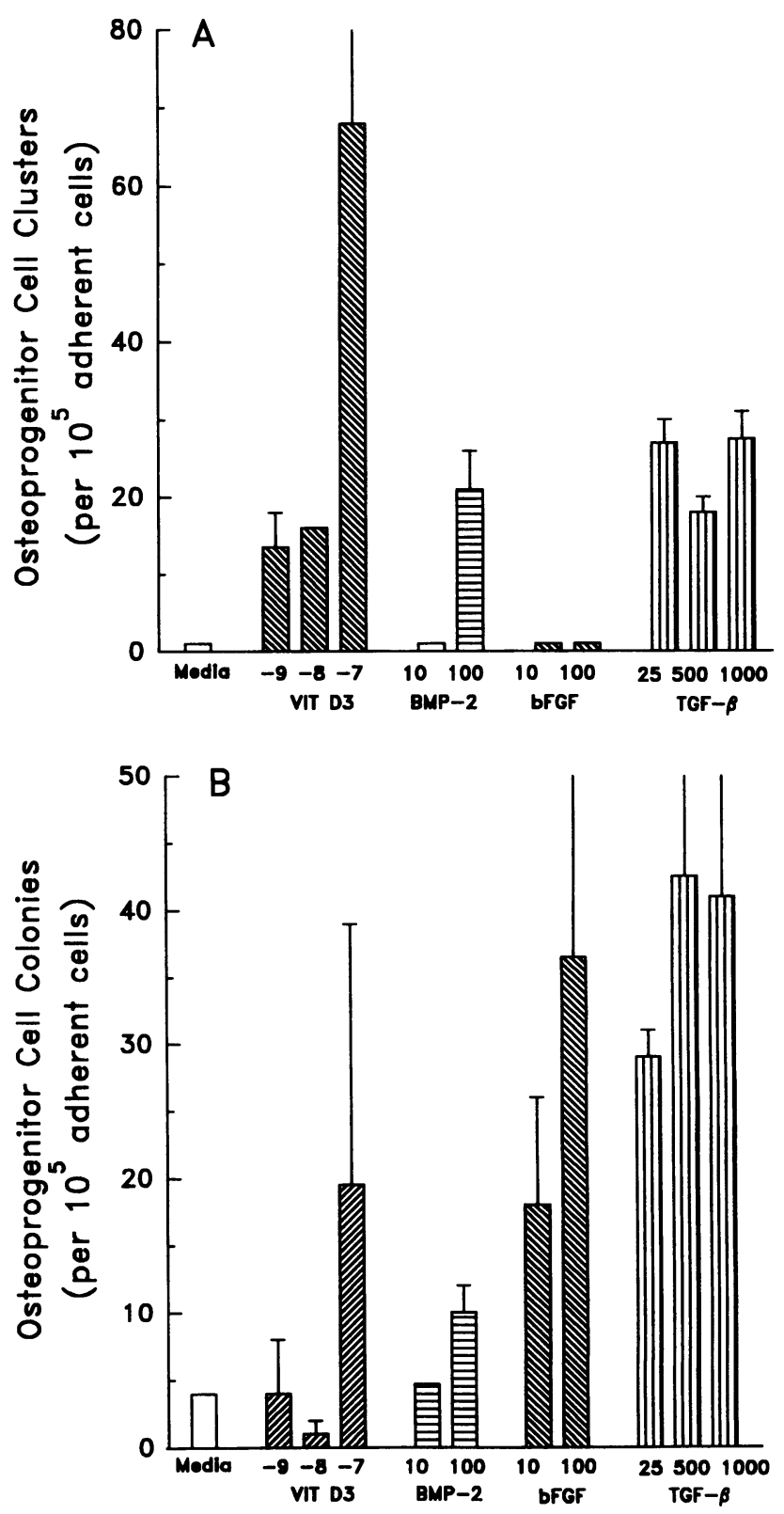

Osteogenic Growth Factors

Figure 5. Responsiveness of osteopoietic colony-forming and clusterforming cells to various growth factors. $(A)$ Osteopoietic cluster-forming cells. These are progenitor cells that demonstrate both a decreased proliferative potential (i. e., decreased cells per colony) and a differential responsiveness to stimuli (compared with colony-forming cells). Thus, these more mature progenitor cells respond best to $1,25-\mathrm{OH}$ vitamin $\mathrm{D}_{3}$ (Vit D3, values are negative logarithms of molarity), intermediately well to both BMP-2 (values are nanograms per milliliter) and TGF- $\beta$ (values are picomolar), but fail to respond to bFGF (values are nanograms per milliliter). Bars labeled as Media are immuneadherent cells cultured in serum-free conditions without the addition of exogenous growth factors. $(B)$ Osteopoietic CFC. In contrast to cluster-forming cells, osteoprogenitor cells which form colonies respond equally well to TGF- $\beta$ and bFGF and intermediately well to $1,25 \mathrm{OH} \mathrm{D}_{3}$ and BMP-2. Considerable donor-to-donor variability exists in the observed frequency of CFC. While this may be due to a lack of growth factor optimization, similar observations have been made on the frequency of hematopoietic progenitor cells in human bone marrow $(7,36)$. 
fibroblast-like morphology, nor do cells within the colonies appear to be fibroblasts (see Fig. 4). Previous work clearly demonstrates that some, but not all, fibroblasts have osteogenic potential (31). However, the lack of phenotypically specific fibroblast markers, and a clear means to purify bone-forming CFU-f, precludes analysis of their relationship to human bone marrow osteoprogenitor cells at present. Likewise, the characterization of isolated human bone marrow-derived bone precursor cells cannot be directly correlated with human trabecular osteoblast outgrowth cultures (which presumably represent mature nonproliferating cells), nor with mouse or rat fetal calvera outgrowth cultures (due to species differences). These limitations notwithstanding, the present data on human osteoprogenitor cells fit well with the developmental sequence of bone cell differentiation described by Lian and Stein (33) in which (osteoprogenitor cell) proliferation precedes extracellular matrix maturation (deposition of collagen and noncollagenous proteins) and mineralization.

Understanding the complex regulatory signals required to coordinate cellular development necessitates an understanding of progenitor cell responses to cytokines, to the surrounding extracellular matrix molecules, and to cell-cell interactions (12, 34). Pragmatically, this requires that investigations into the control of a given cellular lineage use purified progenitor cell populations, serum-free culture conditions, and purified (e. g., recombinant) growth factors. We have shown that human bone marrow-derived bone progenitor cells can be purified by immunological selection for bone protein antigens, cultured in chemically defined, serum-free conditions, and stimulated with purified, bone-active growth factors. The study of these cells will be important to the understanding of bone cell biology in health and disease.

\section{Acknowledgments}

The authors are indebted to Dr. Jeffrey Bonadio for helpful discussions and critical reading of the manuscript; Dr. J. Lynn Williams for additional careful review of the manuscript; Dr. Steve Clarke for supplying recombinant BMP-2; Dr. Milan Usukokovich for supplying vitamin $\mathrm{D}_{3}$; S. Sipple for technical assistance; and Rebecca Hauke for careful manuscript preparation.

This study was supported in part by National Institutes of Health grant AG08777. M. W. Long is an Established Investigator of the American Heart Association.

\section{References}

1. Urist, M. R., R. J. DeLange, and G. A. M. Finerman. 1983. Bone cell differentiation and growth factors. Science (Wash. DC). 220:680-686.

2. Jotereau, F. W., and N. M. Le Douarin. 1978. The developmental relationship between osteocytes and osteoblasts: a study using the quail-chick nucleus marker in endochondrial ossefication. Dev. Biol. 63:253-265.

3. Le Douarin, N. M. 1973. A feulgin-positive nucleolus. Exp. Cell Res. 77:459-469.

4. Fishman, D. A., and E. D. Hay. 1962. Origin of osteoclasts from mononuclear leukocytes in regenerating newt limbs. Anat. Rec. 143:329-339.

5. Ash, P., J. F. Loutit, and K. M. S. Townsend. 1980. Osteoclasts derived from haematopoietic stem cells. Nature (Lond.). 283:669-670.

6. Coccia, P. F., W. Krivitt, J. Cervenka, C. Clawson, J. H. Kersey, T. H. Kim, M. E. Nesbit, M. K. C. Ramasy, P. I. Warkinten, S. L. Teitelbaum, et al 1980. Successful bone-marrow transplantation for juvenile malignant osteopetrosis. N. Engl. J. Med. 302:701-708.

7. Long, M. W., R. J. Hutchinson, L. L. Gragowski, C. H. Heffner, and S. G. Emerson. 1988. Synergistic regulation of human megakaryocyte development. $J$. Clin. Invest. 82:1779-1786.

8. Long, M. W., and C. H. Heffner. 1988. Detection of human megakaryocyte antigens by solid-phase radioimmunoassay. Exp. Hematol. 16:62-70.

9. Long, M. W., J. L. Williams, and K. G. Mann. 1990. Expression of bone- related proteins in the human hematopoietic microenvironment. J. Clin. Invest. 86:1387-1395

10. Stenner, D. D., R. W. Romberg, R. P. Tracy, J. A. Katzman, B. L. Riggs, and K. G. Mann. 1984. Monoclonal antibodies to native noncollagenous bonespecific proteins. Proc. Natl. Acad. Sci. USA. 81:2868-2872.

11. Shull, S., R. P. Tracy, and K. G. Mann. 1989. Identification of a vitamin D responsive protein on the surface of human osteosarcoma cells. Proc. Natl. Acad. Sci. USA. 86:5405-5410.

12. Long, M. W., R. Briddell, A. W. Walter, E. Bruno, and R. Hoffman. 1992. Human hematopoietic stem cell adherence to cytokines and matrix molecules. $J$. Clin. Invest. 90:251-255.

13. Nomura, S., A. J. Wills, D. R. Edwards, J. K. Heath, and B. L. M. Hogan. 1988. Developmental expression of 2ar (osteopontin) and SPARC (osteonectin) RNA as revealed by in situ hybridization. J. Cell Biol. 106:441-450.

14. Holland, P. W. H., S. J. Harmper, J. H. McVey, and B. L. M. Hogan. 1987. In vivo expression of mRNA for the $\mathrm{Ca}++$-binding protein SPARC (osteonectin) revealed by in situ hybridization. J. Cell Biol. 105:473-482.

15. Termine, J. D., H. K. Kleinman, S. W. Whitson, K. M. Conn, M. L. McGarvey, and G. R. Martin. 1981. Osteonectin, a bone-specific protein linking mineral to collagen. Cell. 26:99-105.

16. Hauschka, P. V., J. B. Lian, and P. M. Gallop. 1975. Direct identification of the calcium-binding amino acid, gamma-carboxyglutamate, in mineralized tissue. Proc. Natl. Acad. Sci. USA. 72:3925-3929.

17. Price, P. A., A. S. Otsuka, J. W. Poser, J. Kristaponis, and N. Raman. 1976. Characterization of a gamma-carboxyglutamic acid-containing protein from bone. Proc. Natl. Acad. Sci. USA. 73:1447-1451.

18. Price, P. A., J. W. Lothringer, S. A. Baukol, and A. H. Reddi. 1981 Developmental appearance of the vitamin K-dependent protein of bone during calcification. Analysis of mineralizing tissues in human, calf, and rat. J. Biol. Chem. 256:3781-3784.

19. Wysocki, L. J., and V. L. Sato. 1978. "Panning" for lymphocytes: a method for cell selection. Proc. Natl. Acad. Sci. USA. 75:2844-2848.

20. Mage, M. G. 1992. Isolation of T and B cells using panning techniques. In Current Protocols in Immunology. J. E. Coligan, A. M. Kruisbeek, E. M. Sevach, and W. Strober, editors. J. Wiley and Sons, New York. 3.5.1-3.5.6.

21. Metcalf, D. 1989. The molecular control of cell division, differentiation commitment and maturation in haematopoietic cells. Nature (Lond.). 339:27-30.

22. Metcalf, D., and N. A. Nicola. 1983. Proliferative effects of purified granulocyte colony-stimulating factor (G-CSF) on normal mouse hemopoietic cells. J. Cell Physiol. 116:198-206.

23. Urist, M. R., K. Sato, A. G. Brownell, T. I. Malinin, A. Lietze, Y. K. Huo, D. J. Prolo, S. Oklund, G. A. M. Finerman, and R. J. DeLange. 1983. Human bone morphogenic protein (hBMP). Proc. Soc. Exp. Biol. Med. 173:194-199.

24. Hauschka, P. V., A. E. Mavrakos, M. D. Iafrati, S. E. Doleman, and M Klagsbrun. 1986. Growth factors in bone matrix. Isolation of multiple types by affinity chromatography on heparin-sepharose. J. Biol. Chem. 261:12665-12674

25. Noda, M., and R. Vogel. 1989. Fibroblast growth factor enhances type b1 transforming growth factor gene expression in osteoblast-like cells. J. Cell Biol. 109:2529-2535.

26. Rodan, S. B., G. Wesolowski, K. Yoon, and G. A. Rodan. 1989. Opposing effects of fibroblast growth factor and pertussis toxin on alkaline phosphatase, osteopontin, osteocalcin, and type I collagen mRNA levels in ROS 17/2.8 cells. J. Biol. Chem. 264:19934-19941.

27. Wozney, J. M., V. Rosen, A. J. Celeste, L. M. Mitsock, M. J. Whitters, R. W. Kriz, R. M. Hewick, and E. A. Wang. 1988. Novel regulators of bone formation: molecular clones and activities. Science (Wash. DC). 242:1528-1534.

28. Metcalf, D. 1977. General features of hematopoietic colony formation. In Hematopoietic Colonies. Springer-Verlag, New York. 60-69.

29. Luria, E. A., M. E. Owen, A. J. Friedenstein, J. F. Morris, and S. A Kuznetsow. 1987. Bone formation in organ cultures of bone marrow. Cell Tissue Res. 248:449-454.

30. Bab, I., B. A. Ashton, D. Gazit, G. Marx, M. C. Williamson, and M. E. Owen. 1986. Kinetics and differentiation of marrow stromal cells in diffusion chambers in vivo. J. Cell Sci. 84:139-151.

31. Ashton, B. A., C. C. Eaglesom, I. Bab, and M. E. Owen. 1984. Distribution of fibroblastic colony-forming cells in rabbit bone marrow and assay of their osteogenic potential by an in vivo diffusion chamber method. Calcif. Tissue Int 36:83-86.

32. Falla, N., J. Van Vlasserelaer, J. Bierkens, B. Borremans, G. Schoeters, and U. Van Gorp. 1993. Characterization of a 5-fluorouricil-enriched osteoprogenitor population of the murine bone marrow. Blood. 82:3580-3591.

33. Lian, J. B., and G. S. Stein. 1992. Concepts of osteoblast growth and differentiation: basis for modulation of bone cell development and tissue formation. Crit. Rev. Oral Biol. Med. 3:269-305.

34. Long, M. W. 1992. Blood cell cytoadhesion molecules. Exp. Hematol. (NY). 20:288-301.

35. Briddell, R. A., and R. Hoffman. 1990. Cytokine regulation of the human burst-forming unit-megakaryocyte. Blood. 76:516-522.

36. Emerson, S. G., Y. C. Yang, S. C. Clark, and M. W. Long. 1988. Human recombinant granulocyte-macrophage colony stimulating factor and interleukin 3 have overlapping but distinct activities. J. Clin. Invest. 82:1282-1287. 